\title{
Contribuições da obra de Paulo Freire nos encontros de cursos pré-universitários populares: redes de indignação e esperança
}

Alan Ricardo Costa1', Tatiane Fernanda Gomes ${ }^{2}$

\begin{abstract}
Resumo
Cursos Pré-Universitários Populares/Pré-Vestibulares Populares (PUPs/PVPs) são ações de democratização do acesso ao ensino e de construção do saber com as classes populares. Além disso, tais cursos podem ser interpretados como redes de indignação e esperança, em função de seu caráter social de subversão e luta contra o sistema educacional tradicional bancário e não freiriano, com conexões em rede estabelecidas para articular mentes, criar significado e contestar o poder. O objetivo deste trabalho é apresentar umas das principais possibilidades de estabelecimento e fortalecimento das conexões em redes entre cursos PUPS/PVPs: a realização de encontros para trocas de experiências, reflexões coletivas e fortalecimento de propostas e lutas populares. Conclui-se que, em tais encontros de cursos populares, há também uma revitalização da obra de Paulo Freire, a partir de inúmeras releituras, o que se mostra urgente e necessário para a educação brasileira atualmente.
\end{abstract}

\section{Palavras-chave}

Educação Popular. Curso Pré-Universitário Popular. Sociedade em Rede.

1. Mestre em Linguística Aplicada pela Universidade Católica de Pelotas, Rio Grande do Sul, Brasil; professor substituto na Universidade Federal da Fronteira Sul, Rio Grande do Sul, Brasil; educador no Curso Pré-Universitário Popular Alternativa e Coletivo Práxis de Educação Popular. E-mail: alan.dan.ricardo@gmail.com.

2. Mestra em Educação pela Universidade Federal da Fronteira Sul, Rio Grande do Sul, Brasil; secretária executiva da Universidade Federal de Santa Maria, Rio Grande do Sul, Brasil. E-mail: tatiane@ufsm.br. 


\title{
Contributions of the work of Paulo Freire in the encounter of popular pre-university courses: nets of indignation and hope
}

Alan Ricardo Costa*, Tatiane Fernanda Gomes**

\begin{abstract}
The Popular Pre-University Course/Popular Pre-Universitary (PUPs/ PVPs) are actions of democratization of access to the education and of construction of knowledge with popular class. Beyond that, these courses can be interpreted as networks of indignation and hope (CASTELLS, 2013), in function of their social characteristic of subversion and struggle against the banking and no-Freirean traditional educational system, with connections in stablished networks to articulate minds, create meaning and contest the power. The aim of this work is to present one of the main possibilities of establishment and strengthening of connections in network among the PUPs/PVPs courses: the achievement of meetings to exchange experiences, collective reflection and proposals and popular struggles strengthening. It is concluded that in these meetings of popular courses, there is also a revitalization of the work of Paulo Freire, through uncountable re-readings, which present itself as urgent and needed to the current Brazilian education.
\end{abstract}

\section{Keywords}

Popular Education. Popular Pre-University Course. Society in Network.

\footnotetext{
* MSc in Applied Linguistics, Catholic University of Pelotas, State of Rio Grande do Sul, Brazil; substitute professor at Federal University of Fronteira Sul, State of Rio Grande do Sul, Brazil; popular educator in the Pré-Universitário Popular Alternativa Course and Coletivo Práxis de Educação Popular. E-mail: alan.dan.ricardo@gmail.com.

** MSc in Education, Federal University of Fronteira do Sul, State of Rio Grande do Sul, Brazil; executive secretary at Federal University of Santa Maria, State of Rio Grande do Sul, Brazil. E-mail: tatiane@ufsm.br.
} 


\section{Introdução}

$\mathrm{Na}$ obra Redes de indignação e esperança: movimentos sociais na era da Internet, o sociólogo espanhol Manuel Castells (2013) aborda manifestações políticas em seu processo de formação, implementação e transformação social. Esses movimentos, em rede - constituindo, inclusive, redes de redes - pautam-se principalmente pelo compartilhamento de significado, pelas trocas de informações e saberes e, além disso, pela contestação de estruturas hegemônicas e poderes em geral. Alguns exemplos trazidos pelo autor são "A revolução das panelas", na Islândia, em 2008, o movimento "Occupy Wall Street", iniciado em 2011 nos EUA, e, no Brasil, as manifestações e protestos de junho de 2013.

Castells (2013) aponta que a constituição dessas redes se dá de formas dinâmicas, suscetíveis a cada contexto e conjuntura. Somando tais aspectos à importância social desses movimentos e suas críticas e contestações às estruturas políticas favorecedoras de desigualdades sociais, temos neles características muito assemelhadas àquelas encontradas nos cursos Pré-Universitários Populares (PUPs) e Pré-Vestibulares Populares (PVPs). Esses cursos podem ser "populares" enquanto voltados às classes populares e/ou enquanto cursos freirianos, isto é, que tentam atuar na perspectiva da educação popular, crítica e libertadora, de Paulo Freire. É nesse sentido que o trabalho desenvolvido pelos cursos populares pode ser entendido como de um "duplo movimento", no qual a "preparação para as provas do vestibular acontece junto com discussões críticas sobre a realidade social e, até mesmo, sobre o próprio processo seletivo do vestibular" (PEREIRA; RAIZER; MEIRELLES, 2010, p. 88).

No presente artigo, ao entendermos os cursosPUPs/PVPscomoaçõesdedemocratização do acesso ao ensino e construção coletiva do saber com as classes populares - e que funcionam em variados contextos sociais em um viés de subversão e luta contra hegemônica do sistema tradicional bancário e não freiriano -, compreendemos também que esses mesmos cursos são redes de indignação e esperança, afinal, cursos populares não são apenas projetos educacionais que lutam contra as barreiras econômicas e sociais da educação nacional: são, também, ações cuja luta mostra-se mais efetiva em rede e que articulam mentes, criam significados e contestam o poder, atributos das redes de indignação e esperança (CASTELLS, 2013).

Tendo em vista as considerações precedentes, o objetivo deste trabalho é apresentar umas das possibilidades de estabelecimento e fortalecimento de redes entre cursos PUPs/PVPs: a realização de encontros de cursos populares, para trocas de experiências, compartilhamento de saberes, articulações de lutas e ações populares etc. Especificamente, as discussões são apresentadas a partir de um evento recente: o IV Encontro de PréUniversitários Populares, realizado em setembro de 2016, em Santa Maria, no Rio Grande do Sul. Foi a partir desse encontro que o PréUniversitário Popular Alternativa (doravante PUP Alternativa) passou a vislumbrar, de forma mais acentuada, o alcance e a potência de uma rede de cursos populares, bem como a urgência do fortalecimento e da expansão dessas conexões.

O presente artigo, nesse viés, encontra-se estruturado da seguinte maneira: inicialmente, são apresentadas as características comuns entre as redes de indignação e esperança e os cursos PUPs/PVPs, a partir da literatura da área e do suporte teórico de Castells (2007, 2013). Posteriormente, é apresentado o curso PUP Alternativa (GOMES et al., 2015), ação extensionista desenvolvida em Santa Maria-RS, 
em suas duas participações em encontros de PUPs/PVPs: o Encontro Regional de cursos PUPs/ PVPs, realizado em 2005, e o IV Encontro de PUPs/PVPs, realizado em 2016. Na sequência, é feita a análise dos trabalhos que compuseram os Anais do IV Encontro de PUPs/PVPs, com vistas à averiguação da importância da obra de Paulo Freire nos cursos, mesmo após tantos anos das publicações originais. Finalmente, são feitas as considerações finais, buscando fomentar e incentivar não só a participação dos cursos PUPs/PVPs nos encontros, mas o fortalecimento das conexões de (e em) rede que se dão a partir de tais eventos, algo fundamental para a educação brasileira na conjuntura atual.

\section{Cursos populares como redes de indignação e esperança}

De poucos participantes para dezenas, centenas e milhares de sujeitos politicamente engajados. Da internet, espaço da autonomia e fora do controle dos governos, para as ruas, os espaços públicos e democráticos. Esses foram os movimentos das redes de indignação e esperança que se popularizaram ao redor do mundo no século XXI. Tais redes caracterizam um "coletivo consciente" (CASTELLS, 2013, p. 158), composto de indivíduos entusiasmados conectados entre si que superaram o medo opressor que se combina com o gatilho da raiva (CASTELLS, 2013). Ainda que heterogêneos esses movimentos sociais compartilham entre si características assemelhadas. Dentre elas, temos como características comuns às redes de indignação e esperança, com base em Castells (2013): (a) conexões de múltiplas formas, em redes multimodais (como redes sociais on-line e off-line, por exemplo); (b) simultaneidade entre o local e o global, (começam em contextos específicos por motivos próprios, mas conectamse ao mundo e atingem a dimensão global); e (c) são redes horizontais, o que favorece a cooperação e a solidariedade, ao passo que reduz a necessidade de lideranças formais.

Há pelo menos três grandes aspectos nos quais os cursos PUPS/PVPs - freirianos e em sinergia com o viés da educação popular - podem ser entendidos como redes de indignação e esperança. O primeiro deles é o papel de emoções - como a raiva, o entusiasmo e o medo - na gênese do movimento social e no desencadeamento da busca por justiça, engajamento social e superação (CASTELLS, 2013). Essas emoções básicas, explica Castells (2013), são as faíscas individuais dos sujeitos que, ao conectarem-se com seus pares, compartilham desses sentimentos, constituindo a rede que cresce gradualmente e passa a sentir e pensar no coletivo. Em Freire (1996), essas emoções não são ignoradas ou apartadas do fazer pedagógico e são comuns a uma educação crítica e popular. Tanto que, em suas obras, o autor lembra-se dos sentimentos - a indignação, a "ira justa" dos enganados e explorados, entre outros (FREIRE, 1996) - como indissociados de uma pedagogia da autonomia e da libertação. Em cursos PUPs/PVPs, tão permeados de relações e interações humanas, tais sentimentos não escapam ou são denegados na sala de aula: a abordagem de temas e tópicos como a desigualdade social, a luta de classes, o machismo, o racismo, a LGBTfobia, as formas de violência suscitam a indignação, o desejo de mudança. Não são sentimentos estimulados superficialmente por determinados temas abordados em aulas, tampouco são fomentados por educadores/as nos/as estudantes como se estes/as não tivessem autonomia e sentissem o que os/as docentes querem que sintam; são, isso sim, sentimentos que, quando emergentes, não são repreendidos ou negligenciados, o que resultam nas constituições das redes. O segundo aspecto em que tais redes se assemelham aos cursos PUPs/PVPs, seguindo a linha das emoções como norteadores de tais movimentos sociais, é a ancoragem na esperança. Ainda que Castells (2013) não 
realce seu conceito filosófico de "esperança", é possível associar ao conceito de Freire (1996) pela semelhança das condições em que esta se dá: contextos de luta, resistência e desejo de transformação social etc. Paulo Freire parte de um conceito de "esperança" que não consiste naquele vulgarmente relacionado à espera, ou "espera vã", mas aquele com o poder de mudar a realidade. Aquela esperança que não é suficiente sozinha, mas necessária, pois, com ela sozinha não se ganha a luta, porém sem ela a luta fraqueja e titubeia" (FREIRE, 1994, p. 5). Se a utopia é o inalcançável ao qual sempre nos encaminhamos na luta, sua conotação não é negativa, mas sim de "esperança" como uma reivindicação à transformação da realidade. $\mathrm{O}$ mesmo vale não só para as redes de indignação e esperança, que carregam em sua gênese $o$ desejo da transformação social, mas também para os cursos PUPs/PVPs, que buscam tais transformações no individual (cada indivíduo que compõe o todo) e no coletivo (a conjuntura no qual se insere). A esperança é o motor de um curso popular freiriano, a engrenagem que nos move para não cairmos no pessimismo, na desesperança e no fatalismo neoliberal (FREIRE, 1996), que nos faria desacreditar que construir uma universidade popular, com as classes populares, por meios dos cursos PUPs/PVPs, é possível.

Finalmente, um terceiro aspecto de aproximação, voltando às características comuns dos movimentos sociais em rede, é a autorreflexão. Castells (2013) sublinha que os movimentos em questão "são profundamente autorreflexivos", questionamse "permanentemente como movimento, e seus participantes como indivíduos, sobre o que são, o que desejam e o que pretendem realizar" (CASTELLS, 2013, p. 163). Os cursos PUPs/PVPs, como bem destaca a revisão da literatura da área, preocupam-se com questões como (1) a cidadania, os direitos humanos e temas sociais de forma geral (ZAGO, 2008); (2) a possibilidade de conciliar educação popular e preparação para o vestibular (MENDES, 2009), (3) a educação para além da sala de aula e das pedagogias tradicionais (GOMES et al., 2015), entre inúmeros outros tópicos.

Cada vez mais as leituras realizadas no âmbito do PUP Alternativa permitem a interpretação de que cursos PUPs/PVPs, tanto individualmente (como rede) quanto coletivamente (como redes de redes), são redes de indignação de esperança. A questão que se desenha dessa interpretação, consequentemente, é: de que forma a comunicação e as articulações dessas redes efetivam-se a ponto de que as conexões sejam fortes e o trabalho colaborativo dos cursos PUPs/ PVPs potencialize-se e torne-se ainda mais profícuo? O crescimento e o fortalecimento de uma cultura de encontros entre tais cursos parece ser um passo importante a ser dado.

\section{0 curso PUP Alternativa}

O PUP Alternativa é um curso popular, criado no ano 2000, por estudantes da Universidade Federal de Santa Maria (UFSM), ligados ao Movimento Estudantil, que estudavam no Centro de Ciências Rurais (CCR). A ideia de criar um cursinho popular surgiu da percepção por esses estudantes da elitização da UFSM, sobretudo no final da década de 1990, aliada ao contexto local marcado pela proliferação de pré-vestibulares pagos, cujos alunos/as eram abundantemente aprovados no vestibular, o que dificultava o acesso de estudantes das classes populares e trabalhadores à universidade.

A proposta foi elaborada e apresentada à Pró-Reitoria de Extensão da UFSM, acolhida, ainda no ano 2000, pelo registro como projeto de extensão. O projeto inicial foi construído com 
base no Pré-Vestibular Desafio ${ }^{3}$, vinculado à Universidade Federal de Pelotas (UFPel) e seguia algumas características deste, como o processo seletivo realizado mediante comprovação de escolaridade, renda e residência, sucedido por entrevista e a realização de atividades periódicas voltadas à cidadania e cultura. Outro aspecto importante na construção da proposta inicial foi a duração do curso: por se tratar de uma proposta afiliada à educação popular, não poderia ser um curso aligeirado, intensivo, como os cursinhos comerciais. Além disso, era prevista a reserva de um horário semanal para discussão de temas de interesse dos estudantes, a "aula de cidadania", mantida até a edição atual, porém com denominações diferentes. A esse respeito, Gomes et al. (2015, p. 144) esclarecem:

A formatação, conteúdo, público, recursos, local e objetivos destas atividades, dependem muito do grupo de educadores de cada edição do Alternativa. De certo modo, o projeto, mesmo mantendo boa parte de educadores de um ano para o outro, (re)começa a cada janeiro, a cada nova formação de início de ano. [...] os rumos e atividades que acontecem a cada ano dependem muito da equipe de trabalho, do entendimento pedagógico e de muitos destes que se envolvem de maneira mais ativa, sejam coordenadores gerais ou educadores das disciplinas.

As aulas deveriam ser realizadas na área central do município de Santa Maria, proporcionando condições de acesso a estudantes das diferentes regiões da cidade e que, muitas vezes, trabalham na região central. A primeira edição do curso foi oferecida no ano 2000 e o processo seletivo e as aulas, realizados no Instituto Estadual de Educação Olavo Bilac, da rede pública estadual. De 2001 a 2006, o curso foi realizado em espaços cedidos por outras escolas da rede estadual, devido à ausência de espaços com a infraestrutura mínima necessária dentro da UFSM. A partir do final de 2006, o curso passou ser realizado no Prédio de Apoio Didático e Comunitário da UFSM, localizado na região central de Santa Maria, e o processo seletivo de 2007 já ofereceu 150 vagas, divididas em quatro turmas de curso extensivo, com atividades diárias, de segunda a sábado ${ }^{4}$. Além da edição anual do curso, foram realizadas duas edições de intensivo, uma no município de São Pedro do Sul, em parceria com a prefeitura municipal, e uma na Escola Estadual de Ensino Fundamental e Médio Augusto Ruschi, na COHAB Santa Marta, em 2004 e 2008, respectivamente. $\mathrm{O}$ projeto tem um estatuto atualizado anualmente, no qual estão descritas as atribuições dos diferentes segmentos de participantes. A condução das aulas fica a cargo dos educadores, dos quais grande parte é estudante de graduação, pós-graduação ou profissionais voluntários. O grupo de educadores é dividido em equipes, por disciplina, com autonomia didático-pedagógica no encaminhamento das aulas, abordando as temáticas e conteúdos referentes ao Exame Nacional do Ensino Médio (ENEM). Cada equipe possui um coordenador, responsável por coordenar a elaboração de materiais didáticos, simulados e orientar a realização de outras atividades, como monitorias, oficinas e projetos paralelos.

Para ingressar como educando/a, é necessário já ter concluído ou estar cursando o ensino médio e passar pelo processo seletivo anteriormente mencionado. Os/as educandos/ as recebem, de forma gratuita, cadernos didáticos elaborados pelos educadores. A Coordenação Executiva do PUP Alternativa é responsável por tarefas

3. Projeto de extensão da Universidade Federal de Pelotas que existe desde 1993, que tem como princípio básico a solidariedade e o dever moral que os estudantes da UFPel, juntamente com as demais pessoas que constroem a história dessa instituição, detêm em relação à grande parcela da sociedade que sustenta o ensino superior sem dele fazer parte. O objetivo é proporcionar a uma parcela da classe trabalhadora o acesso à universidade pública. 4. De segunda a sexta no período da noite, das $19 \mathrm{~h}$ às $22 \mathrm{~h} 30 \mathrm{~min}$, e aos sábados à tarde, das $14 \mathrm{~h}$ às $17 \mathrm{~h}$. 
administrativas e de interlocução e planejamento junto à Pró-Reitoria de Extensão, oferta de horas de atividades de formação continuada, atividades extraclasses para os educandos e participação em eventos acadêmicos pertinentes. Nos últimos anos, a participação em eventos se deu tanto no âmbito institucional, com trabalhos apresentados na Jornada Acadêmica Integrada (JAI/UFSM) e semanas acadêmicas de cursos, quanto em eventos regionais, nacionais e internacionais, relacionados, como: $\mathrm{XI}$ Congreso Iberoamericano de Extensión Universitaria (2011), Fóruns de Estudos Leituras de Paulo Freire (2015 e 2016), Encontros de PUPs (2015 e 2016), 6o e 70 Congresso Brasileiro de Extensão Universitária (2014 e 2016), 2o Congresso de Extensão da Associação de Universidades do Grupo de Montevidéu (2015) e a publicação de trabalhos acadêmicos alusivos ao projeto em periódicos, como a Revista UNIFREIRE.

\section{Encontros de PUPs/PVPs: entre dois vieses (que se complementam)}

Podemos argumentar que os cursos PUPs/PVPs contam com dois tipos de eventos que influenciam, sobretudo em termos metodológicos, seus encontros, sejam eles nacionais, estaduais, regionais, municipais etc. De um lado, temos os eventos universitários (seminários, encontros, simpósios, mesas, oficinas, palestras e congressos em geral), que refletem em grande parte o formato acadêmico dos encontros de PUPs/PVPs. De outro, temos as assembleias e demais espaços deliberativos comuns dos sindicatos e outras organizações políticas, responsáveis por inspirar as discussões e os encaminhamentos da agenda política, com a qual os PUPs/ PVPs dialogam direta ou indiretamente. Sobre os congressos universitários da atualidade, para além das críticas ao pragmatismo produtivista que tem tomado o ensino superior e prejudicado o desenvolvimento científico no que tange à pesquisa crítica e criativa, Paula (2012, p. 55) lembra que o "antigo perfil acadêmico do intelectual humboldtiano, vinculado ao modelo alemão de universidade do século XIX, sozinho com o silêncio de sua biblioteca ou laboratório, é hoje espécie em extinção", o que se pode interpretar positivo. Afinal, na atualidade, mostra-se necessário um cientista minimamente responsivo à sociedade. Nesse viés, atualmente, é preciso considerar que

pertencermos a um ou vários grupos de pesquisa, a redes de pesquisa e publicações, e a participação em congressos, encontros, seminários nacionais e internacionais fazem parte intrínseca do cotidiano da vida acadêmica, como um elemento motivador do processo de produção científica. (PAULA, 2012, p. 55).

Os encontros de cursos PUPs/PVPs são importantes neste aspecto: há, a partir deles, uma constituição de rede e publicização de trabalhos e estudos que não só fomentam as trocas de experiências e pesquisas desenvolvidas, mas que também legitimam tais trabalhos no que se entende por produção científica.

Os trabalhos desenvolvidos dentro dos cursos PUP/PVP, em geral, contemplam o ensino, a pesquisa e a extensão e, como tais, não devem ser marginalizados ou depreciados no âmbito universitário, pelo contrário, é necessário adentrarem os espaços acadêmicos aquelas pesquisas oriundas de cursos PUPS/ PVPs, com novas epistemologias mais populares, pós-estruturalistas, pós-modernas e póscolonialistas, que ressignifiquem o pensamento tradicional já superado do fazer científico.

Sobre as assembleias e demais espaços deliberativos - comuns em sindicatos e grupos políticos - é preciso ressaltar que tais influências podem ser elucidadas por variadas razões, a saber: (1) a gênese e história dos cursos PUPs/PVPs é bastante atrelada aos 
movimentos sindicais brasileiros (MENDES, 2009), principalmente o Movimento Sindical ou o Movimento Comunitário (ZAGO, 2008, p. 153); (2) há, ainda hoje, dentro dos cursos PUPs/PVPs a abordagem de temas que vão além dos conteúdos preparatórios para o vestibular, e que, por conseguinte, dialogam com os temas e tópicos abordados por grupos políticos, principalmente aqueles que reivindicavam direitos às classes populares; e (3) parte significativa das experiências de cursos PUPs/PVPs surge de projetos liderados pelos diretórios acadêmicos e movimento estudantil (ZAGO, 2008, p. 153), o que faz com que tais cursos contem com educadoresacadêmicos, que trazem desses espaços práticas democráticas de debates e encaminhamentos políticos. Assim, a influência das assembleias e demais espaços colaborativos se dá, dentro dos encontros de PUPs/PVPs, no fomento às discussões e encaminhamentos das conjunturas políticas e problemas sociais de cada contexto no qual cada curso popular se insere.

Portanto, a metodologia de encontros de cursos PUPs/PVPs não conta apenas com discussões teóricas e publicações acadêmicas, que são importantes socialmente e não devem ser negligenciadas pelos cursos populares: tais espaços servem, também, para a análise da agenda geral dos cursos e encaminhamentos de atividades práticas de protesto ou intervenção e reivindicações de direitos políticos, principalmente aqueles estudantis, referentes a políticas de acesso e permanência no ensino superior.

A seguir, temos dois exemplos de encontros de cursos populares que, por um lado, publicizaram suas pesquisas e apresentaram (re)leituras da obra de Paulo Freire e temas afins, e, por outro, abordaram pautas políticas importantes aos próprios cursos e seu público: as classes populares.

\section{a. Encontro Regional}

No ano de 2005, o PUP Alternativa promoveu o II Encontro Regional de Cursos PréVestibulares Populares ${ }^{5}$. O evento foi realizado entre os dias 12, 13 e 14 de novembro de 2005, na UFSM, e teve como temática: "Violência, Educação e Liberdade". Participaram cursinhos populares de todo o estado: Rubem Berta - Faculdade Porto-Alegrense (FAPA), Zumbi dos Palmares, Alternativa Cidadã/UFRGS, CEUE (Centro do Estudantes Universitários de Engenharia da UFRGS), Resgate e Organização Não Governamental para Educação Popular (ONGEP), Antígona Zumbi dos Palmares, Desafio Universidade Federal de Pelotas (UFPEL), PUP Alternativa e Práxis.

A solenidade de abertura reuniu representantes do Movimento Brasileiro de Educadores Cristãos (MOBREC), Grupo de Pesquisa em Educação e Território (GPET/ UFSM), Sindicato dos Metalúrgicos, Movimento Nacional de Luta pela Moradia, em um movimento de aproximação entre os PVPs e os movimentos sociais.

A programação propunha espaços de compartilhamento de experiências e reflexões sobre educação popular, práticas metodológicas, desafios e problemas enfrentados pelos educadores e educandos, como o valor das taxas de inscrição no vestibular e evasão. Apesar de estar prevista na programação a construção deliberativa da Carta do Encontro, tal documento não foi localizado. Além das discussões já mencionadas, a programação também proporcionou momentos culturais como a apresentação do Grupo de Dança Afro Ewá Dandaras, vinculado ao Museu Treze de Maió${ }^{6}$.

5. Não foram localizadas informações referentes ao I Encontro de Pré-Vestibulares Populares

6. O Clube Social Negro, criado em 1903 por ferroviários negros do município de Santa Maria, Rio Grande do Sul, pela mobilização da comunidade negra e por alunos da Museologia/Unifra e antigos sócios foi transformado em Museu Comunitário no ano de 2001 e, em 2004, foi tombado como patrimônio histórico municipal pelo papel no desenvolvimento da cidade. 
Foto 1 - Participantes do II Encontro Regional de Cursos Pré-Vestibulares Populares.

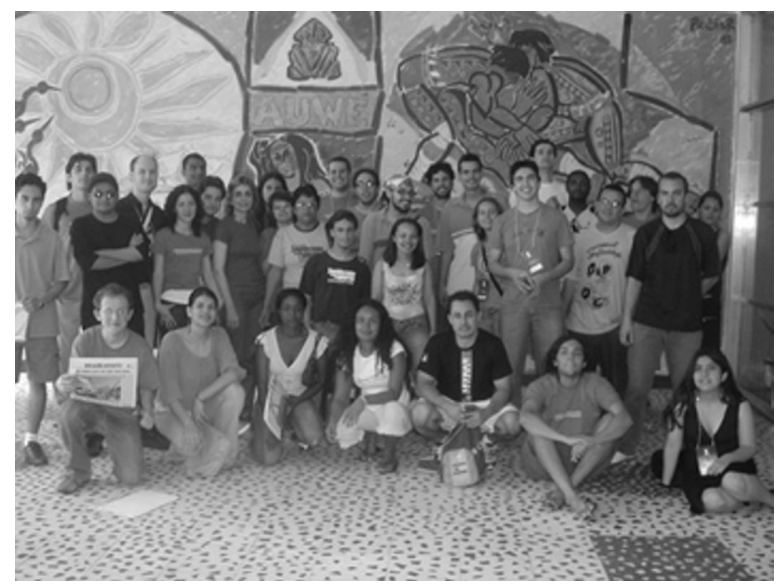

Fonte: Acervo Alternativa (2005).

\section{b. IV Encontro de PUPs/PVPs}

Em 2016, o PUP Alternativa teve a honra de promover e sediar o IV encontro de PréUniversitários Populares, evento de abrangência nacional. A realização do encontro foi sugerida um ano antes, no III Encontro, realizado na Universidade Federal de Rio Grande (FURG), pelo Programa de Auxílio ao Ingresso nos Ensinos Técnico e Superior (PAIETS), Núcleo Educamemória e PET Conexões de Saberes da Educação Popular e Saberes Acadêmicos daquela instituição. O objetivo foi tornar esses eventos periódicos e itinerantes, a fim de intensificar o diálogo e a cooperação entre os cursos populares.

Consta que o primeiro encontro de pré-vestibulares populares foi realizado na cidade de Florianópolis, Santa Catarina, no ano 2000; o segundo ocorreu em 2003, na capital Rio de Janeiro (NASCIMENTO, 2002). Em 2015, foi realizado o III encontro de PUPs, já com a nova denominação "pré-universitários populares", mais adequada ao contexto atual.

Reunir cursos populares para troca de experiências e interlocução de saberes e fortalecer o contato entre os participantes foram as principais motivações para a realização do encontro, que propôs a integração entre os cursinhos populares e outras ações de extensão das diferentes regiões do Brasil. O debate em torno da presença das classes populares no ensino superior teve a companhia da discussão em torno da educação como um todo no país, promovendo a reflexão sobre (1) a formação inicial e continuada de educadores, (2) Educação de Jovens e Adultos (EJA), (3) o papel e a atuação da extensão universitária e (4) os desafios da presença da educação popular em espaços formais de educação.

A programação previu espaços de reflexão em torno da importância desse tipo de evento, discussão de temas relativos à universidade e à educação popular, além de destacar os espaços de integração, auto-avaliação, proposições para o futuro, e propostas para o $\mathrm{V}$ Encontro de PUPs. Também foram oferecidas quatro oficinas $^{7}$ - 1) Artes da Cena, 2) Ficção brasileira contemporânea: por um novo paradigma estético e político, 3) Repensando o silêncio

7. A descrição das oficinas está disponível nos Anais do evento: <http://media.wix.com/ugd/ab4d62 b9ab7a3391474bfc9463160861198798.pdf >. 
do/a educando/a e a fala do/a educador/a e 4) Por que ama de leite ou globeleza? O papel do pós-abolição na construção da imagem da mulher - e três momentos culturais: o primeiro realizado por educandos do PUP Alternativa, em intervenção orientada pelos educadores da equipe de Teatro; o segundo, com Nei D'Ogum, militante do movimento negro e da causa LGBT e membro da Comunidade de Terreiro Ilê Axé Ossanha Agué, com a intervenção "Encantado Negro", e o terceiro a apresentação de representantes do movimento Hip Hop local.

É possível dividir os participantes do IV Encontro de PUPs em dois grandes grupos, tomando por critério a vinculação do curso a alguma Instituição de Ensino Superior. Entre os que não se vinculam às universidades estão: Gestão Estudantil Universitária Integrar - Florianópolis/SC, Território Popular - Porto Alegre/RS, GESTUS - Coletivo do Projeto Integrar, voltado à permanência nas universidades públicas - Florianópolis/SC, além do Cursinho Popular da ACEPUSP (Associação Cultural dos Educadores e Pesquisadores da Universidade de São Paulo) - São Paulo/SP. Os demais PUPs/PVPs apresentam alguma vinculação a instituições de ensino superior, a começar pelo anfitrião do evento, o PUP Alternativa, e o Práxis
Coletivo de Educação Popular, ambos da UFSM. Da Universidade Federal do Rio Grande (FURG) participaram quatro cursos: Paideia Educação Popular, Curso Preparatório Popular Fênix, Grupo de Apoio Educacional Maxximus e Quinta Pré-Vestibular. Todos fazem parte do Programa de Auxílio ao Ingresso nos Ensinos Técnico e Superior (PAIETS), que existe desde 2007 e agrupa cursos pré-universitários e preparatórios para o ingresso em cursos técnicos nos municípios de Rio Grande/RS, São José do Norte/RS, Capão do Leão/RS e Santo Antônio da Patrulha/RS. Participaram também o Curso PréUniversitário Alternativo PIES (Projeto de Inclusão ao Ensino Superior), da Universidade Federal de Uberlândia (UFU) - Uberlândia/MG, o Cursinho Educação e Cidadania (CEC), da Universidade Federal de São Carlos (UFSCAR) - Sorocaba/SP, e o Pré-Vestibular Esperança Popular da Restinga, ação de extensão do Departamento de Educação e Desenvolvimento Social (DEDS/UFRGS) e promovido em parceria com a comunidade do Bairro Restinga. Finalmente, vale citar o LEME Oficinas Preparatórias para o ENEM, vinculado à Universidade Federal do Pampa (UNIPAMPA), que oferta oficinas preparatórias que fazem parte de um projeto de extensão do curso de Ciências Humanas do Campus São Borja e são realizadas nas dependências da instituição.

Figura 1 - Cursos PUPs/PVPs particpantes do IV Encontro de Pré-Universitários Populares.

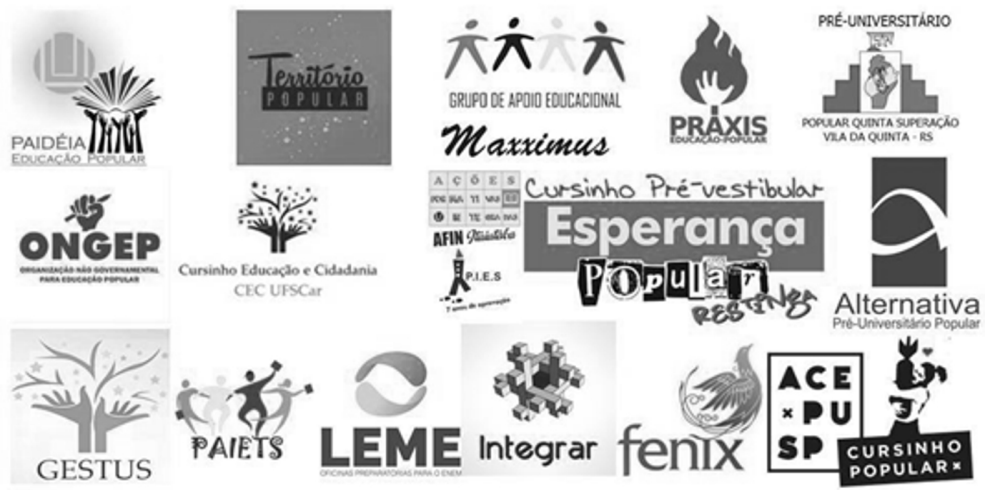

Fonte: Acervo Alternativa (2016). 
Foto 2 - Participantes do IV Encontro de Pré-Universitários Populares.

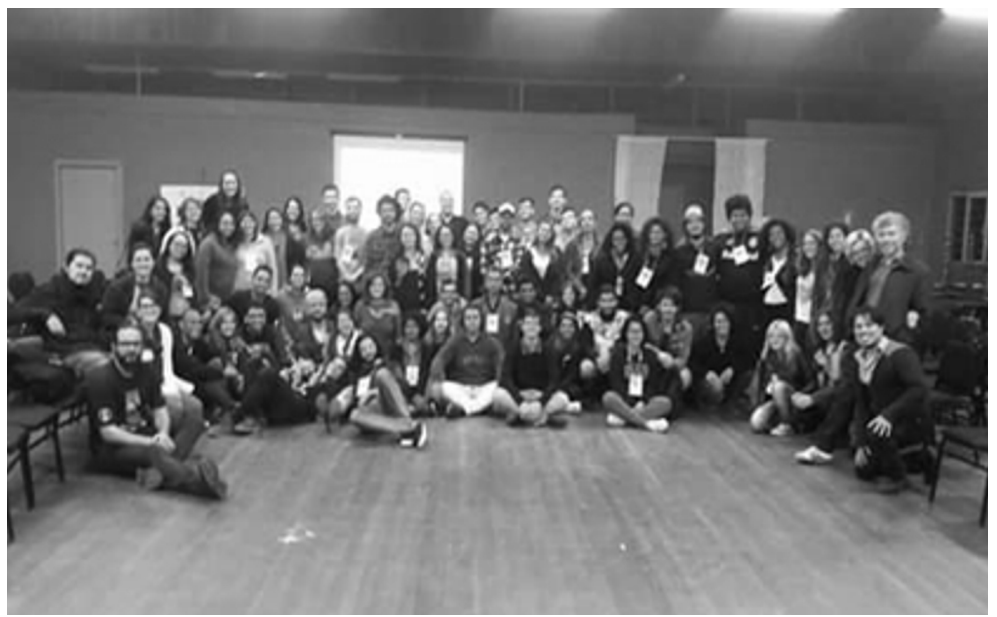

Fonte: Acervo Alternativa (2016).

\section{A obra de Paulo Freire nos cursos PVP/ PUP}

É visível a influência de Paulo Freire nos cursos PUPs/PVPs. Mendes (2009), por exemplo, destaca que a matriz de influências de tais cursos, isto é, a relação com os movimentos sociais (movimento estudantil, movimento negro e também comunidades eclesiais de base), acaba sendo entrecruzada pelo pensamento desse educador. Isso se dá seja por se tratar de uma modalidade de educação não formal, seja pela crítica à "educação bancária", que não problematiza os problemas vividos pelos educandos com vistas à sua emancipação (MENDES, 2009, p.3). Vale reafirmar uma vez mais, dessa vez nas palavras de Nascimento (2002), que, na maioria dos cursos PUPs/PVPs,

há preocupações que extrapolam a preparação para o vestibular. Trata-se de preocupações políticas, que se explicitam nos discursos dos seus participantes, nas propostas e nas práticas dos cursos, que vão desde atividades desenvolvidas em sala de aula, que visam à construção de uma nova consciência em seus educandos (consciência racial, de gênero, de classe, dos problemas sociais etc.), passam por seminários, fóruns de discussões, assembleias, negociação de isenções e bolsas com universidades, ações judiciais, formulação de propostas para facilitar o acesso e a permanência de estudantes das classes populares no ensino superior e democratizar a educação e o acesso ao conhecimento (NASCIMENTO, 2002, p. 40).

Temos, destarte, uma influência freiriana que se dá tanto na dimensão política quanto na dimensão pedagógica, consideradas indissociáveis na perspectiva crítica. Os cursos PUPs/PVPs, portanto, são (ou podem ser, em maior ou menor escala) freirianos enquanto (1) projetos engajados socialmente nas questões políticas que o circulam, (2) ações que abordam temáticas sociais pertinentes às classes populares, como essas sublinhadas por Nascimento (2002), e (3) cursos cuja abordagem de temas, mesmo aqueles relativamente apartados do contexto social (como tende a ser o caso de alguns dos conteúdos pré-vestibulares exigidos), mostrase popular na metodologia, ou seja, um tema tratado de forma crítica, reflexiva, questionadora, problematizadora, não maniqueísta.

Assim, mostra-se fundamental que 
cada curso e cada sujeito que o compõe educadores, educandos e demais envolvidos - avaliem e pensem continuamente seu grau de comprometimento com a perspectiva da educação popular, da pedagogia crítica e do viés freiriano de forma geral.

Os encontros de PUPs/PVPs, enquanto espaço de compartilhamento e construção coletiva do saber entre cursos populares, podem ser um bom termômetro de avaliação deste grau de envolvimento com uma pedagogia não meramente "pré-vestibular".

\section{Os Anais do IV Encontro de PUPs/PVPs}

A análise dos Anais do IV Encontro de cursos PUPs é usada, aqui, para ilustrar a forma como tais congressos contribuem na reflexão e na troca de experiências e pesquisas desenvolvidas nos (e a partir dos) cursos populares. Ao total, doze artigos completos, seis resumos expandidos e quinze resumos simples compõem os anais, além de treze produções artísticoliterárias e resumos de apresentação das quatro oficinas realizadas ao longo do IV Encontro.

A maioria dos trabalhos se ocupa da apresentação dos cursos PUPs/PVPs que participaram do IV Encontro, e/ou especificam atividades desenvolvidas a partir de tais cursos, o que demonstra a natureza colaborativa e compartilhada das experiências vivenciadas. Relatos de experiências e trabalhos sobre a "biografia" de cada curso compõem o grupo maior de estudos publicados.
A importância da obra freiriana nos trabalhos listados mostra-se de forma mais explícita naquelas pesquisas que abordam Paulo Freire e suas proposições pedagógicas. E mostrase de forma mais implícita naqueles que, com base no legado de Freire, lançam novos olhares sobre temáticas já presentes, ou que começam a sefazer notar nos cursos PUPs/PVPs no séculoXXI.

Dentre os trabalhos que abordam mais explicitamente a obra freiriana, duas das publicações se destacam. A primeira delas é o ensaio de Nascimento (2016), que resgata a relação de Paulo Freire com o marxismo. Por um lado, tal estudo aponta em quais aspectos e concepções do marxismo historicamente construído se apresentam em obras como a Pedagogia do Oprimido (1987), e, por outro, contrapõe algumas críticas atuais a Paulo Freire. Afinal, recentemente, por questões políticopartidárias, o nome de Paulo Freire vem sendo atrelado de forma bastante rasa e perversa a uma doutrinação marxista, razão pela qual a figura dele tende a ser hostilizada em manifestações recentes $^{8}$. No ínterim desses ataques, projetos que cerceiam a educação e a instrumentalizam e reduzem, como o "Escola Sem Partido", seguem propagando, de forma nada neutra, uma pseudoneutralidade na educação, o que Paulo Freire, nas primeiras páginas da Pedagogia da Esperança (1994), salienta ser bastante contraditório e questionável.

O segundo trabalho, de autoria de Dias $(2016)^{10}$, aborda a perseguição de órgãos de segurança brasileiros a Paulo Freire no Chile por parte de órgãos como o Centro de Informações

8. Mais informações podem ser lidas em sites de notícia como Pragmatismo Político <http://www. pragmatismopolitico.com.br/2015/03/onu-responde-manifestantes-que-pediram-basta-de-paulo-freire.html> e BBC Brasil: <http://www.bbc.com/portuguese/noticias/2015/07/150719_entrevista_romao_paulofreire_cc>. É importante ressaltar que as manifestações que criticaram Paulo Freire, em 15 de março de 2015, possuem motivações políticas e ideologias totalmente opostas àquelas de 2013 debatidas por Castells (2013).

9. Para mais informações, ver: <http://www.programaescolasempartido.org/>.

10. Este, e alguns outros trabalhos submetidos como artigos completos, foram selecionados para compor um e-book ou dossiê em periódico acadêmico com a temática "Paulo Freire e cursos pré-universitários populares". Ao total, sete artigos completos foram selecionados para compor esta compilação extra, e não foram considerados neste artigo por a publicação estar no prelo. Ressalva-se, contudo, que são trabalhos que também se relacionam à obra de Freire. No caso do trabalho de Dias (2016) e outros, o artigo completo foi selecionado, e o resumo simples foi publicado nos Anais. 
do Exterior (Ciex), vinculado ao aparato repressivo da ditadura civil-militar brasileira, o Sistema Nacional de Informação (SNI), o Ministério das Relações Exteriores (MRE) e a Divisão de Segurança e Informações (DSI). Tal vigilância ocorreu porque Freire se destacava dentro da comunidade de brasileiros exilados, pois seu método crítico de alfabetização influenciou os projetos educacionais dos presidentes chilenos Eduardo Frei Montalva (1964-1970) e Salvador Allende (1970-1973).

Os demais trabalhos constantes nos Anais, ainda que não tratem especificamente de Paulo Freire, contam com as obras do patrono da educação brasileira no embasamento teórico. Ao todo, sete artigos, seis resumos expandidos e sete resumos simples ${ }^{11}$ referenciam diretamente trabalhos de Freire.

A partir de uma análise quantitativa das referências bibliográficas dos trabalhos, tornase viável a averiguação da popularidade de determinadas obras. Vale destacar a Pedagogia do Oprimido (1987) como a obra mais popular de Paulo Freire, sendo listada nas referências de quinze trabalhos. Em segundo lugar, A Pedagogia da Autonomia (1996) consta nas referências de quatro trabalhos, possivelmente por sua apresentação de práticas pedagógicas inerentes à construção da autonomia de educandos/as, algo de grande valor para os cursos PUPs/PVPs.

A importância do ato de ler foi a terceira obra mais citada, referenciada por três trabalhos, enquanto que Educação como Prática da Liberdade foi referenciado por outros dois estudos. As obras Pedagogia da Esperança (1994), A educação na cidade, Professora sim, tia não - cartas a quem ousa ensinar e Extensão ou Comunicação? (1971) são referenciadas uma vez cada nos Anais do IV Encontro.

Talvez o maior encaminhamento e sugestão de leitura seja a Pedagogia da Esperança (1994), cujo subtítulo é “Um reencontro com a
Pedagogia do Oprimido". Esta, por ser a mais referenciada e, possivelmente, a obra magna de Paulo Freire, possui releituras fundamentais para um Brasil diferente e reformulado duas décadas depois. A Pedagogia da Esperança (1994) é, por assim dizer, um amadurecimento, um conjunto de reflexões de um Brasil mais neoliberal, mais assemelhado ao cenário dos anos 1990, nos quais os cursos PUPs/PVPs se consolidaram e se popularizaram, razão pela qual esta obra possa ser um norte complementar à Pedagogia do Oprimido (1987). Talvez, pelo número expressivo de cursos PUPs/PVPs na forma de projeto de extensão universitária, a obra Extensão ou Comunicação? (1971) também pudesse obter maior visibilidade na agenda de leituras dos cursos populares, tendo em vista a linha tênue entre uma extensão catequizadora messiânica assistencialista, no sentido mais perverso da palavra, contrária a uma extensão em diálogo horizontal, permeada de respeito entre os saberes de educandos/as e educadores/as.

O suporte teórico de Freire se deu, sobretudo, na concepção de educação subjacente às propostas pedagógicas dos cursos PUPs/PVPs. Em melhores palavras, para além da menção a Paulo Freire, é notório que os cursos populares buscam a oposição aos modelos tradicionais de educação, pautados na centralização do saber na figura do professor, muito assemelhada a uma educação bancária. Os cursos PUPs/PVPs opõem-se, por conseguinte, ao modelo fordista de acúmulo de estudantes homogeneizados e silenciados para que o professor possa transmitir, mais facilmente, informação para o maior número de pessoas conglomerado naquele espaço físico aproveitado ao máximo, e num menor intervalo de tempo possível, muito comum às salas de cursos pré-vestibular particulares. Além disso, há também a divergência entre estes cursos na própria concepção de o que é ensinar e aprender,

11. Especificamente sobre os resumos simples, destaca-se: quatro deles foram submetidos sem referências bibliográficas, tendo em vista que, segundo as normas do evento, estas eram facultativas. 
sendo que nos cursos populares isso é entendido como processual e mútuo: educando e educador se educam mutuamente (FREIRE, 1996).

Pelas razões acima que cursos populares recorrem à obra freiriana. Mesmo após décadas das primeiras publicações de Freire, há nelas o suporte teórico necessário para a constante reflexão que norteia o caminho dos cursos PUPs/ PVPs rumo a uma educação crítica, humana, libertadora, Popular com $\mathrm{P}$ maiúsculo, não apenas construída "para" as classes populares, mas "com" elas, como se caracteriza a educação popular.

\section{Considerações finais}

Zago (2008, p. 151) salienta que os cursos PUPs/PVPs não são "iniciativas isoladas", mas sim ações que refletem

a preocupação nacional com a problemática do acesso à universidade pública e com o aumento da demanda da população pelo ensino superior impulsionada pela expansão do ensino básico, pela urbanização e pelas transformações do mercado de trabalho.

Temos, portanto, cursos diferentes entre si, que vivem realidades distintas, mas com objetivos comuns. Daí a importância de pensarmos em rede de indignação e esperança.

De forma mais acentuada, uma cultura de encontros entre cursos PUPs/PVPs podem ser entendidos como os nós desta rede, em que as linhas se tocam e se conectam. Tais encontros são os pontos de conexões mais "fortes", aqueles que potencializam o diálogo, a interação, as trocas de experiência e, sobretudo, os encaminhamentos para atividades de lutas populares e transformação social. Os encontros não se restringem apenas a debates teóricos em uma perspectiva acadêmica/universitária, tampouco se limitam ao debate da conjuntura política e/ou às políticas públicas educacionais do Brasil: há uma mescla desses dois vieses, que se complementam para contribuir indissociavelmente na formação humana, acadêmica, profissional e política, de todos os envolvidos: educadores, educandos/ as e demais sujeitos. E uma das formas como esta contribuição se dá é no resgate da obra de Paulo Freire. No caso específico dos Anais do IV Encontro de PUPs, realizado em Santa Maria-RS, em 2016, é notório que a obra freiriana ainda é o suporte teórico central nas concepções de educação e fazer pedagógico.

Conclui-se, assim, que encontros regulares de cursos PUPs/PVPs, por revitalizarem a obra de Paulo Freire, a partir de inúmeras releituras, ao passo que fortalece o próprio curso e seu viés de trabalho horizontal e democrático de educação popular, são fundamentais para a educação brasileira atual.

\section{Referências}

CASTELLS, M. A sociedade em rede. 10. ed. São Paulo: Paz e Terra, 2007. 96 p.

Redes de indignação e esperança: movimentos sociais na era da internet. Rio de Janeiro: Zahar, 2013. 290 p.

DIAS, C. M. Á. A perseguição de órgãos de segurança brasileiros ao educador Paulo Freire no Chile. In: ENCONTRO DE PRÉ-UNIVERSITÁRIOS POPULARES, 6., 2016, Santa Maria. Anais... Santa Maria: Editora da UFSM, 2016.

FREIRE, P. Extensão ou comunicação? Rio de Janeiro: Paz e Terra, 1971. 96 p. 
Pedagogia do oprimido. 17. ed. Rio de Janeiro: Paz e Terra, 1987. 253 p.

. Pedagogia da esperança: um reencontro com a pedagogia do oprimido. 3. ed. Rio de Janeiro: Paz e Terra, 1994. 336 p. 1996. 144 p.

Pedagogia da autonomia: saberes necessários à prática educativa. São Paulo: Paz e Terra,

GOMES, T. F. et al. Para além da sala de aula: práticas educativas potencialmente emancipatórias no Pré-Universitário Popular Alternativa (UFSM). Revista Unifreire, São Paulo, v. 1, p. 140-154, 2015.

MENDES, M. T. Cursinhos populares pré-universitários e educação popular: uma relação possível? In: FÓRUM DE LEITURAS PAULO FREIRE, 11., 2009, Porto Alegre. Anais... Porto Alegre: Editora da UFGRS, 2009.

NASCIMENTO, A. do. Universidade e cidadania: o movimento dos cursos pré-vestibulares populares. Revista Lugar Comum: Estudos de Mídia, Cultura e Democracia, Rio de Janeiro, n. 17, p. 45-60, 2002.

NASCIMENTO, C. O. do. Existe influência marxista no pensamento freiriano? In: ENCONTRO DE PRÉ-UNIVERSITÁRIOS POPULARES, 6., 2016, Santa Maria. Anais... Santa Maria: Editora da UFSM, 2016.

PAULA, M. de F. C. de. Políticas de avaliação da educação superior e trabalho docente: a autonomia universitária em questão. Universidade e Sociedade, Brasília, Ano XXI, n. 49, p 51-61, jan. 2012.

PEREIRA, T. I.; RAIZER, L.; MEIRELLES, M. A luta pela democratização do acesso ao ensino superior: o caso dos cursinhos populares. Revista Espaço Pedagógico, Passo Fundo, v. 17, n. 1, p. 86-96, jan.-jun. 2010.

ZAGO, N. Cursos pré-vestibulares populares: limites e perspectivas. Perspectiva, Florianópolis, v. 26, n. 1, p. 149-174, jan.-jun. 2008. doi: https://doi.org/10.5007/2175-795x.2008v26n1p149.

Submetido em 13 de março de 2017.

Aprovado em 2 de abril de 2017. 